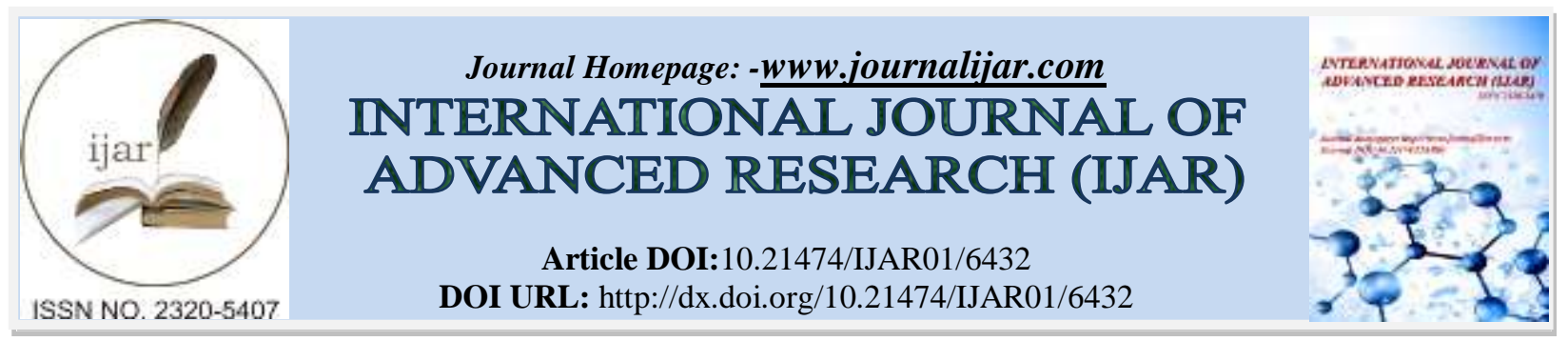

RESEARCH ARTICLE

\title{
EFFECT OF MOIST HEAT THERAPY ON THE VISIBILITY AND PALPABILITY OF VEINS BEFORE PERIPHERAL INTRAVENOUS CANNULATION OF PATIENTS UNDERGOING CHEMOTHERAPY.
}

\section{K. Simarpreet ${ }^{1}$, R. Ruchika ${ }^{2}$, S. Prabhjot ${ }^{3}$ and K. Jasbir ${ }^{4}$.}

1. College of Nursing, Dayanand Medical College and Hospital, Ludhiana, Punjab-141001, India.

2. Assistant Professor, College of Nursing, Dayanand Medical College and Hospital, Ludhiana, Punjab-141001, India.

3. Associate Professor College of Nursing, Dayanand Medical College and Hospital, Ludhiana, Punjab-141001, India.

4. Principal cum Professor,College of Nursing, Dayanand Medical College and Hospital, Ludhiana, Punjab141001, India.

\section{Manuscript Info}

Abstract

Manuscript History

Received: 03 December 2017

Final Accepted: 05 January 2018

Published: February 2018

\section{Introduction:-}

The common routes of drug administration are classified as systemic route and local route. Systemic route consist Enteral route (oral, sublingual and rectal) and Parenteral route (intravenous, intramuscular, subcutaneous and inhalation $)^{7}$.Intravenous cannulation is the most frequently used and is the fastest way to deliver fluids and medications throughout the body, so most of the hospitals prepare for the peripheral cannulation procedure to administer medication ${ }^{7,1}$.

Peripheral venous cannulation is the commonest and frequently used method for intravenous therapy ${ }^{5}$ Before the procedure of cannulation, palpation of the vein is important in determining the condition of the vein. The criteria for good vein are: bouncy and soft, well supported, refill when depressed, visible and straight, have a large lumen ${ }^{4}$ Most common veins on the non-dominant forearm are most suitable, if the cannula has to remain in position for the length of time ${ }^{3}$.

Peripheral IV catheter insertion is a common nursing procedure often required for the administration of various drugs including Chemotherapy. Chemotherapy is one of the cancer treatment modalities that provide cure, control, or palliation. Most of the chemotherapeutic drugs are also delivered intravenously ${ }^{8}$. Due to the repeated course and irritant and vesicant nature of the chemotherapeutic drugs, the cancer patients often pose a problem for cannulation ${ }^{5}$. The rate of complications resulting from IV cannulation can be reduced by proper visualization and palpation of vein before IV cannulation. 
There are various measures (like warming of the limb, gently tapping over the site, applying tourniquets 5-10 $\mathrm{cm}$ proximal to the selected site or asking the patients to clench and relax their hands and by hanging the arm down etc. ${ }^{6}$ ) which the nurses can use independently in their practice for making the veins suitable for IV cannulation in case of difficult cannulation and to prevent and manage its complications.

Application of heat at the IV insertion site has been shown to increase the vein visualization. Fink et al (2009) examined the effect of dry versus moist heat application on the improvement of IV insertion rates. They concluded that dry heat was 2.7 times more likely than moist heat to result in successful IV insertion on the first attempt ${ }^{2}$.

As many methods are available for easy identification of veins. One of the beneficial methods is application of heat on the visualization of veins which improves the insertion of IV cannula. So Investigator felt that there should be any method which increase the visibility and palpability of veins and undertook the study to assess the effectiveness of moist heat therapy on the visibility and palpability of veins and outcomes of IV cannulation.

\section{Material and Methods:-}

Figure 1 depicts that Randomized control design was employed using 'parallel group design' to carry out the study. The study was conducted on patients undergoing intravenous cannulation before chemotherapy, admitted in the oncology wards of DMC\& Hospital, Ludhiana. The study includes the patients who had undergone peripheral intravenous cannulation on upper limbs below the elbow (veins of dorsum of hands and forearm) and had vein assessment score 1, 2 and 3 (according to Vein Assessment Scale).

The sample size was total 100 patients i.e. 50 subjects from control group and 50 subjects from experimental group. 'Simple random sampling technique' i.e. flip and coin method (head side of the coin was considered for the experimental group subject and tail side for control group subject) was used to randomly allocating the patients in experimental and control group.

An interview schedule was used to collect the demographic data of the patients (includes age, gender, marital status, religion, education, occupation, habitat, dietary habits, Socio-economic status and life style), an observation and interview methods were used to assess the clinical profile of the patients ( includes diagnosis, duration of illness, duration of treatment, stage of cancer, treatment other than chemotherapy, chemotherapy regimen, chemotherapy cycle, interval between two cycles, type of chemotherapy, site of cannulation, BMI, skin moisture, skin turgor and presence of hairs over site).

Vein Assessment Scale (Lenhardt 2002) a standardized 5 point rating scale (Score 1 - Vein neither visible nor palpable, 2- Vein visible but not palpable, 3 -Vein is barely visible and palpable, 4- Vein is visible and palpable, 5Vein is clearly visible and palpable) was used to assess the palpability and visibility of peripheral veins. The reliability of tool is predetermined as the tool is standardized. Inter-rater method was used in present study to calculate the reliability of 5 point rating scale and it was found to be reliable ( $\mathrm{r}=0.8)$. A Pilot study was conducted on 10 subjects with 5 subjects in each group i.e. experimental and control group, to assess the feasibility of the study in oncology wards of DMCH, Ludhiana.

The permission was taken from ethical committee of DMCH to carry out the study. The subjects were informed about the purpose, objectives and benefits of the research study; written consent was taken from each subject. Full autonomy was given to participate in research and withdraw at any time. Pre-intervention assessment includes baseline data (Socio-demographic, clinical and skin assessment) and assessment of visibility and palpability of veins before IV cannulation as per vein assessment scale in both the experimental and control group. During intervention, in experiment group 'moist heat therapy' was provided for intermittent 10 minutes (a cotton handkerchief soaked in warm water of temperature range $39-40^{\circ} \mathrm{C}$ was firstly applied for 5 minutes then taken out and again soaked and reapplied for 5 minutes), prior to IV cannulation and in control group, routine care was given before IV cannulation. Post interventional assessment (assessment of visibility and palpability of veins) was done in both groups before IV cannulation as per vein assessment scale. Furthermore success rate of cannulation, number of pricks and duration of whole procedure was also assessed. 
Figure 1:-

\section{RANDOMIZED CONTROL TRIAL DESIGN}

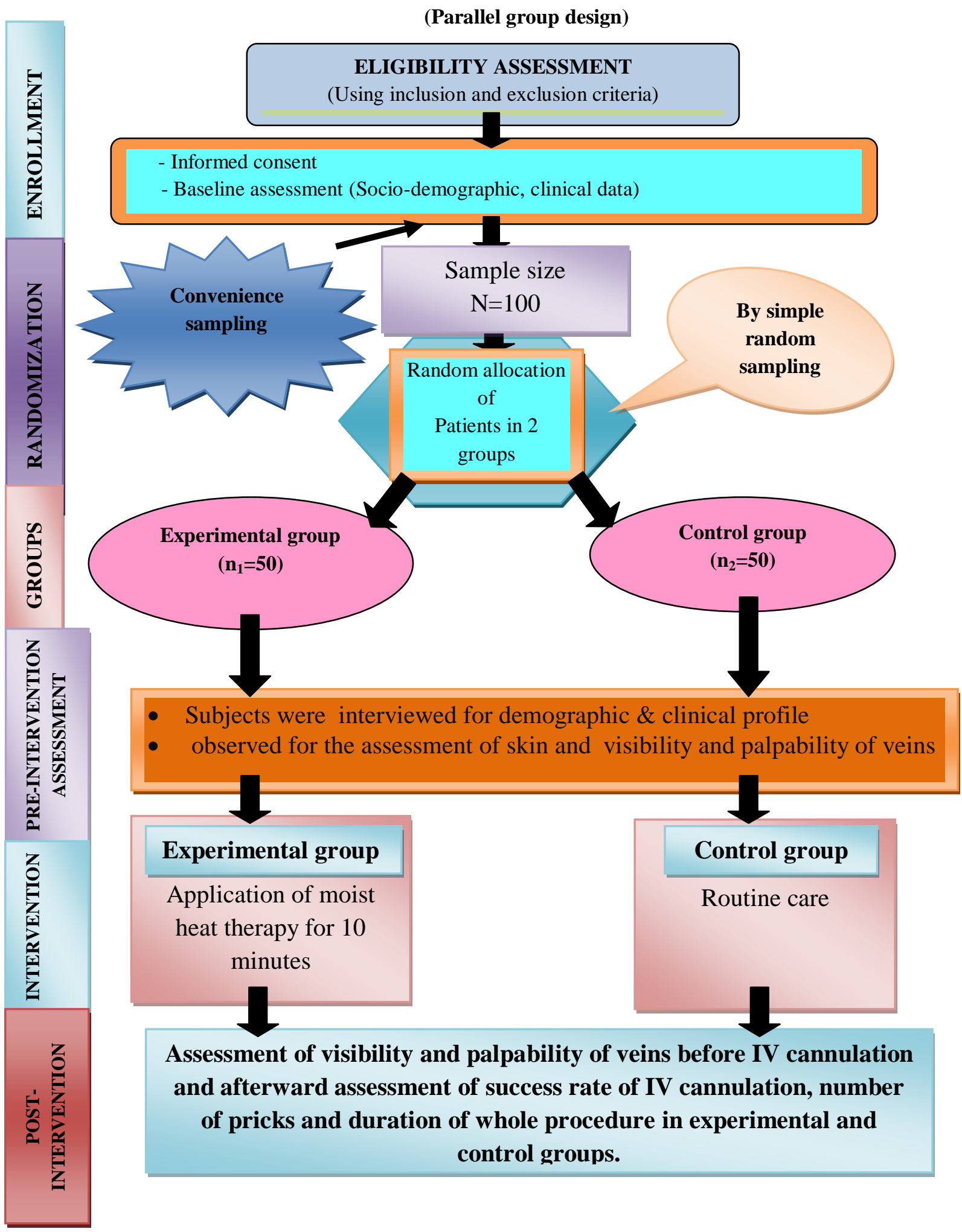




\section{Results:-}

As per socio-demographic profile it is found that out of total 100 subjects near to $2 / 3^{\text {rd }}$ i.e. (73\%) subjects was under age group 41-60 years of age with mean age 48.12 \pm 11.70 and more than half (53\%) subjects were males and majority $(86 \%)$ were married while less than half $(40 \%)$ subjects were holding secondary level of education in experimental and control group. Moreover, out of total 100 subjects most of $(75 \%)$ subjects were non-working and $(61 \%)$ were consuming vegetarian diet while more than half $(57 \%)$ belonged to rural habitat and less than half $(42 \%)$ subjects were from lower middle (III) socio economic category in experimental and control group.

As per clinical profile, it was found that out of total 100 subjects less than half (48\%) subjects was suffered from cancer of reproductive system and less than two third (68\%) of subjects were getting chemotherapy with duration 111 months whereas, more than half of subjects $(55 \%)$ were receiving only chemotherapy as a treatment modalities and most of subjects (78\%) were receiving infusion type chemotherapy, less than half of subjects (44\%) were receiving Paclitaxel and Carboplatin as a chemotherapy regimen and near to half of subjects (48\%) were receiving chemotherapy cycle between 1-6. Furthermore less than half subjects (43\%) had IV cannulation on dorsum of right hand and near to half of subjects (48\%) were having normal (18.5-24.5) BMI. As per skin assessment profile Out of 100 Subjects majority of subjects $(71 \%)$ were having dry skin, $(62 \%)$ had normal Turgor and majority of subjects $(80 \%)$ were having presence of less hairs on site.

Table 1 illustrates the percentage distribution of subjects as per pre interventional vein assessment score among experiment and control group. It was revealed that both the groups were statistically homogenous as per vein assessment scale $(\mathrm{p}>0.005)$. Percentage distribution of subjects as per VAS (vein assessment scale) revealed that in experiment group $\left(\mathrm{n}_{2}=50\right)$ most of the subjects $26(52 \%)$ had pre interventional VAS 2 (vein visible but not palpable) followed by $16(32 \%)$ with score of 3 (vein barely visible and palpable) and few subjects 8 (16\%) had VAS 1 (vein neither visible nor palpable). While in control group $\left(n_{1}=50\right)$ most of subjects $22(44 \%)$ had VAS 3 (vein is barely visible and palpable) followed by 20(40\%) had VAS 2 (vein visible but not palpable) and few subjects i.e. $8(16 \%)$ had VAS 1 (vein neither visible nor palpable).

Figure 2 shows the post-interventional vein assessment score in control and experimental group. It revealed that in the control group $\left(\mathrm{n}_{1}=50\right)$ majority of subjects $22(44 \%)$ had vein assessment score 3 (vein barely visible and palpable) whereas post-interventional in experiment group $\left(\mathrm{n}_{2}=50\right)$ most of subjects $32(64 \%)$ had vein assessment score 4 (vein clearly visible and palpable). Hence moist heat was significantly effective in improving visibility and palpability of veins.

Table 2 illustrates the comparison of vein assessment score and outcome of I/V cannulation in both experimental and control group. The mean vein assessment score was more in experimental group as compared to control group (3.92 \pm 0.60 . vs. $2.28 \pm 0.72, \mathrm{t}=12.27, \mathrm{p}=0.001 * *)$ respectively. This denotes that the application of moist heat therapy had shown statistically significant difference in improving visibility and palpability of veins before peripheral intravenous cannulation as indicated by $\mathrm{p}=0.000$, hence the null hypothesis is rejected.

The mean rate of successful $\mathrm{I} / \mathrm{V}$ cannulation was more in experimental group as compared to control group $(1.96 \pm 0.18$ vs. $1.86 \pm 0.35, \mathrm{t}=1.50, \mathrm{p}=0.14)$, moreover the number of pricks was significantly reduced in experimental group than control group $(1.13 \pm 0.39$ vs. $1.74 \pm 0.75, \mathrm{t}=2.78, \mathrm{p}=0.001 * *)$ respectively. Significant reduction in duration of whole procedure was also observed in experimental group than control group (1.18 $\pm 0.56 \mathrm{vs}$. 2.04 \pm 1.14 , $\mathrm{t}=4.78, \mathrm{p}=0.001 * *)$.

Table 3 depicts the pre-interventional and post-interventional vein assessment score in experimental group. It shows that pre-interventional Vein assessment score $(2.16 \pm 0.68)$ of subjects were in the range of 1-3, out of which, majority of the subjects $26(52 \%)$ had score 2(vein visible but not palpable) followed by $16(32 \%)$ with score 3 (barely visible and palpable) followed by $8(16 \%)$ with score 1 (neither visible nor palpable). The post-interventional Vein assessment scores (3.92 \pm 0.60$)$ of subjects improved to score range of 3-5, in which maximum number of subjects $32(64 \%)$ had scored 4 (vein visible and palpable) followed by 11(22\%) with score 3(vein barely visible and palpable) and 7(14\%) had scored 5(clearly visible and palpable).

It illustrates that post-interventional mean vein assessment score was significantly higher as compared to preinterventional mean vein assessment score $\left(3.92 \pm 0.60\right.$ vs $2.16 \pm 0.68$, mean difference $\left.=1.76, \mathrm{t}=24.05, \mathrm{p}=0.000^{* * * *}\right)$. 
Figure 3 depicts the pre-interventional and post-interventional mean $\%$ of vein assessment score in experimental group. It shows that mean $\%$ vein assessment score among patients of post interventional group was (78.4\%) more as compare to the mean \% vein assessment score in pre interventional group (45.6\%). This denotes that the application of moist heat therapy had shown statistically significant difference in improving visibility and palpability of veins before peripheral intravenous cannulation as indicated by $\mathrm{p}=0.000^{* * * *}$.

Table 1:- Pre-interventional comparison of VAS (Vein Assessment Score) in experiment and control group. N=100

\begin{tabular}{|c|c|c|c|}
\hline Vein assessment score & $\begin{array}{c}\text { Control } \\
\text { group } \\
\mathbf{n}_{1}=\mathbf{5 0} \\
\mathbf{f}(\%)\end{array}$ & $\begin{array}{c}\text { Experimental } \\
\text { group } \\
\mathbf{n}_{2}=\mathbf{5 0} \\
\mathbf{f}(\%)\end{array}$ & $\chi^{2} \quad$ Statistics \\
\hline 1(Vein neither visible nor palpable) & $8(16)$ & $8(16)$ & \multirow{5}{*}{$\begin{array}{c}1.73 \\
\mathrm{df}=2 \\
\mathrm{p}=0.421^{\mathrm{NS}}\end{array}$} \\
\hline 2(Vein visible but not palpable) & $20(40)$ & $26(52)$ & \\
\hline 3(Vein is barely visible and palpable) & $22(44)$ & $16(32)$ & \\
\hline 4(Vein is visible and palpable) & ---- & ---- & \\
\hline 5(Vein clearly visible and palpable) & ---- & ---- & \\
\hline
\end{tabular}

NS: Non-significant $(\mathrm{p} \geq 0.05)$

Vein assessment score 4 and 5 were excluded.

Figure 2:- Comparison of post interventional Vein assessment score in control and experimental group

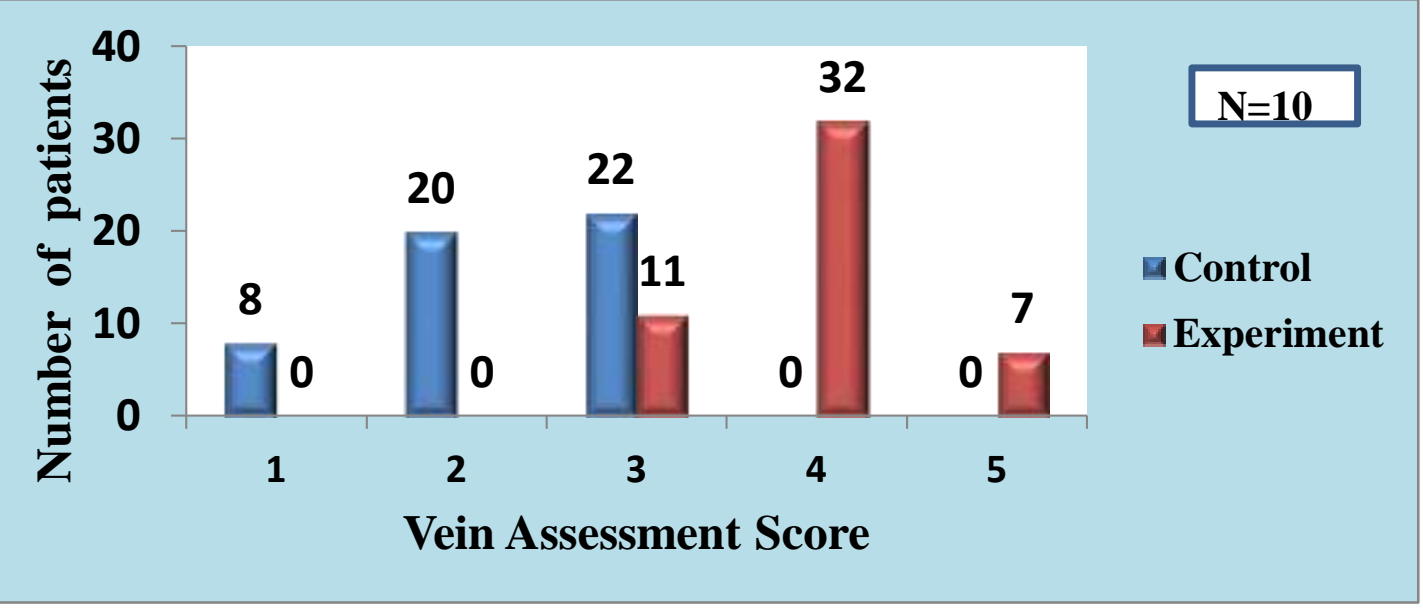

Subjects with vein assessment score (VAS) 4 and 5 were not included in the study

Table 2:-Comparison of the post interventional Vein Assessment Score (VAS) in control and experimental group.

\begin{tabular}{|c|c|c|c|c|}
\hline \multirow[b]{3}{*}{ Variables } & \multirow{2}{*}{\multicolumn{2}{|c|}{ Mean \pm SD }} & \multirow[b]{3}{*}{ t value } & \multirow[b]{3}{*}{$p$ value } \\
\hline & & & & \\
\hline & $\begin{array}{c}\text { Control } \\
\mathbf{n}_{1}=50\end{array}$ & $\begin{array}{c}\text { Experiment } \\
\mathbf{n}_{2}=50\end{array}$ & & \\
\hline VAS & $2.28 \pm 0.72$ & $3.92 \pm 0.60$ & 12.27 & $0.00^{* *}$ \\
\hline I/V cannulation & $1.86 \pm 0.35$ & $1.96 \pm 0.18$ & 01.50 & $0.14^{\mathrm{NS}}$ \\
\hline No. of pricks & $1.74 \pm 0.75$ & $1.13 \pm 0.39$ & 02.78 & $0.00^{* * *}$ \\
\hline $\begin{array}{c}\text { Duration of whole } \\
\text { procedure }\end{array}$ & $2.04 \pm 1.14$ & $1.18 \pm 0.56$ & 04.78 & $0.00 *$ \\
\hline
\end{tabular}

NS -Non significant $(\mathrm{p} \geq 0.05)$

*significant $(\mathrm{p}<0.05)$

Mean VAS difference in both groups $=1.64 \pm 0$. 
Table 3:-Effects of the intervention on the Vein Assessment Score in experimental group. $\mathbf{N = 5 0}$

\begin{tabular}{|c|c|c|c|c|}
\hline Score & Peripheral veins status & $\begin{array}{c}\text { Pre intervention } \\
\mathbf{n = 5 0} \\
\mathbf{f}(\mathbf{\%})\end{array}$ & $\begin{array}{c}\text { Post intervention } \\
\mathbf{n = 5 0} \\
\mathbf{f}(\mathbf{\%})\end{array}$ & \multirow{2}{*}{$\mathrm{t}$ value } \\
\hline 1 & Neither visible nor palpable & 08 & 0 & \multirow{2}{*}{$\chi_{\text {yc }}^{2}=73.92$} \\
$\mathrm{df}=4$ \\
$\mathrm{yynnn}$
\end{tabular}

Figure 3:-Comparison of Pre interventional and post interventional vein assessment score in experimental group.

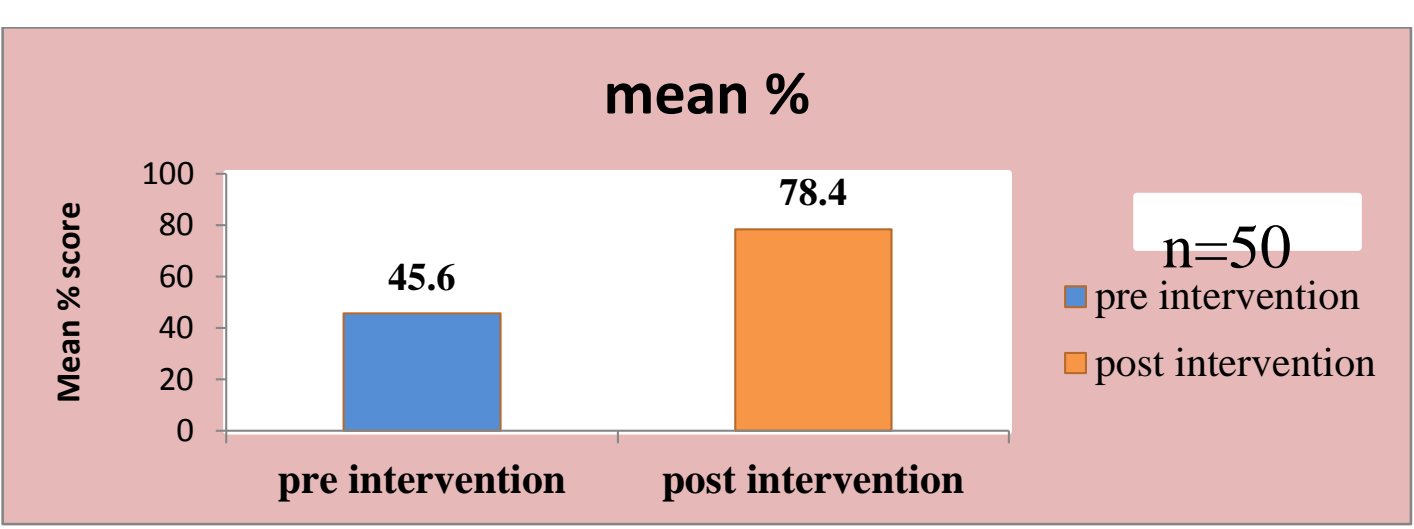

$\mathrm{n}=50$

\section{Discussion:-}

The findings of present study showed that the mean vein assessment score in experiment group i.e. $3.92 \pm 0.60$ was more as compare to mean vein assessment score of control group i.e. $2.28 \pm 0.72(\mathrm{t}=12.27, \mathrm{p}=0.001)$. The mean difference of vein assessment score in control and experiment group is 1.64.

The results are supported by the finding of another study i.e. a double blinded RCT, conducted by Fink Regina M, Hjort Ellen et al (2009) in USfound thatIn moist heat group the mean pre warming vein status was $3 \pm 1.4$ and the mean status was $3.8 \pm 1.2$ after the warming $(\mathrm{t}=4.88, \mathrm{p}=0.001)^{2}$.

A study was conducted by Lenhardt R, Seybold T et al (2002) in Austria,concluded that local warming of the hand and lower arm increased the rate of successful insertion of peripheral venous cannula and reduced the insertion time $^{6}$.

The findings of the present study showed that The mean rate of successful I/V cannulation was more in experimental group as compared to control group $(1.96 \pm 0.18$ vs. $1.86 \pm 0.35, \mathrm{t}=1.50, \mathrm{p}=0.14)$, moreover the number of pricks was significantly reduced in experimental group than control group $(1.13 \pm 0.39$ vs. $1.74 \pm 0.75, \mathrm{t}=2.78, \mathrm{p}=0.001)$ respectively. Significant reduction in duration of whole procedure was also observed in experimental group than control group ( $1.18 \pm 0.56$ vs. $2.04 \pm 1.14, \mathrm{t}=4.78, \mathrm{p}=0.001)$.

Findings are supported by a study conducted by Lenhardt R, Seybold T et al (2002) in Austria,found thatlocal warming of the hand and lower arm increased the rate of successful insertion of peripheral venous cannulae and reduced insertion time in neurosurgical patients and patients with leukaemia ${ }^{6}$.

The findings of the present study showed that It shows that in pre-interventional group $(\mathrm{n}=50)$ majority of subjects $26(52 \%)$ were had vein assessment score 2(i.e. vein is visible but not palpable) while in post-interventional group $(\mathrm{n}=50)$ maximum number of subjects $32(64 \%)$ were had vein assessment score 4 (i.e. vein visible and palpable. It 
also found that post-interventional mean vein assessment score 3.92 \pm 0.60 was more as compare to preinterventional mean vein assessment score i.e. $2.16 \pm 0.681(\mathrm{t}=24.05, \mathrm{p}=0.000)$ in experiment group.

The results are supported by the finding of a study, was conducted by Kaur M, Kaur S and P Firuza D (2011) in PGIMER Prior to intervention none of the patients had visible and palpable veins. After the intervention $40 \%$ subjects had clearly visible and easily palpable peripheral veins (score 5). One third (33.3\%) had the score of 4 i.e. visible and palpable veins. In $11.7 \%$ subjects the veins were visible but not palpable (score 2 ) after the intervention ${ }^{5}$.

\section{Conclusion:-}

The present study concluded that moist heat therapy is significantly highly effective in improving visibility and palpability of veins $(\mathrm{p}=0.000)$. The moist heat therapy was also significantly effective in terms of successful cannulation, decreased duration of whole procedure and reduced the number of pricks.

\section{Acknowledgment:-}

Fore mostly author is thankful to the Almighty Waheguru, for providing her wisdom to accomplish this task. The author wants to acknowledge her mentors and Director/ Principal of College of Nursing DMCH, Ludhiana for their steady guidance and assistance for completion of this research project. Author also wants to express deepest gratitude to her family members for their continuous support throughout the study

\section{Funding:-}

This research received no specific grant from any funding agency in the public, commercial or not-for-profit sectors.

Ethical approval and consent to participate:-

This study was approved by the Institutional Ethics Committee of DMCH (Dayanand Medical College and Hospital), Ludhiana under the reference number: DMCH/R\&D/2014/275 and Consent for participation in the study was taken from each study subject.

\section{Registration of study:-}

This study has been registered in CTRI (Clinical Trials Registry-India) under reference no- REF/2017/12/016545. The registration number for this trial is CTRI/2018/01/011433.

\section{References:-}

1. Dougherty L. Intravenous cannulation. Nursing standard 1996; 11:47-54.

2. Fink M R et al. The impact of dry versus moist heat on peripheral catheter insertion in hematologic oncology patient. Oncol Nurs Forum. 2009 July; 36(4): 1-11.

3. Jackson A. Performing peripheral intravenous cannulation. Professional nurse. 1997 October; 13: 21-25.

4. John Stone M. The effect of lorazepam on the vasoconstriction of fear. Anesthesia 1976; 31: 868-72.

5. Kaur M et al. Effect of moist heat therapy on the visibility and palpability of peripheral veins before peripheral venous cannulation of patients undergoing chemotherapy. NMJ 2011 July; 7: 99-104.

6. Lenhardt $\mathrm{R}$ et al. Local warming and insertion of peripheral venous cannulation single blinded prospective randomized controlled trial and single blinded randomized crossover trail. BMJ 2002 August 24; 325: $409-10$.

7. Verma P et al. Routes of drug administration. IJPSR 2010; 1(1): 54-59.

8. Vesicants chemotherapy extravasations pdf [Internet] 1989 January. Cited on 26.09.15 Available from: URL:http:// www.cincinnatichildrens.org/9065455. 